\title{
Precipitating factors leading to decompensation of heart failure in patients attending a tertiary care centre of Nepal.
}

\author{
Suman Adhikari', Ratna Mani Gajurel' ${ }^{1}$, Chandra Mani Paudel ${ }^{1}$, Hemanta Shrestha', Sanjeev Thapa ${ }^{1}$, \\ Surya Devkota', Vijay Yadav', Manju Sharma' ${ }^{1}$
}

${ }^{1}$ Department of Cardiology, Manmohan Cardiothoracic Vascular and Transplant Centre, Kathmandu, Nepal.

\section{Corresponding Author:}

Suman Adhikari

Department of Cardiology, Manmohan Cardiothoracic Vascular and Transplant Centre,

Kathmandu, Nepal.

E-mail: adhikari11613@gmail.com

ORCID ID NO: 0000-0001-8402-5325

Cite this article as: Adhikari S, Gajurel RM, Paudel CM, et al. Precipitating factors leading to decompensation of heart failure in patients attending a tertiary care centre of Nepal. Nepalese Heart Journal 2020; Vol 17 (1), 17-21

Submitted date: $18^{\text {th }}$ February 2020

Accepted date: $8^{\text {th }}$ April 2020

\begin{abstract}
Background and Aims: Heart failure is one of the debilitating conditions in patients with various forms of heart disease. It can have impacts on various aspects of the life of a patient. There have been few studies on the etiological aspects and precipitants of heart failure in the Nepalese population. The aim of our study is to find out the major factors that lead to decompensation of heart failure in patients who already have established heart failure. Methods: This study was a single-centre, prospective, observational study conducted in the emergency department of Manmohan Cardiothoracic Vascular and Transplant Centre (MCVTC) from 1st June 2019 to 30th November 2019. Hundred and one patients with established heart failure in the past, who presented again with decompensated heart failure were enrolled. Results: The mean age of the patients was 62.81 years $(\mathrm{SD}=15.92)$. Factors responsible for acute decompensation of heart failure were identified in $95.0 \%$ of patients included in the study. The most common factor identified was poor compliance with medications and diet and fluid intake (38.6\%). Next to it was arrhythmia identified in about $35.6 \%$ of cases.Other important factors responsible for decompensation in our study were infection (12.8\%), anemia (4.9\%) and ischemia $(2.9 \%)$. Conclusion: Preventable and identifiable factors are responsible for the decompensation of heart failure. Most of these factors can be modified with the use of proper patient counseling/patient education, thereby reducing recurrent hospital admissions and economic burden to the patient and the government as well.
\end{abstract}

Keywords: Decompensation; Heart failure; Precipitating Factors.

DOI: https://doi.org/10.3126/njh.v17i1.28798

\section{Introduction}

Heart failure is defined as a complex clinical syndrome resulting from structural and functional impairment of ventricular filling or ejection of blood. ${ }^{1}$ There have been very few studies on etiological aspects and factors leading to the decompensation of heart failure in the Nepalese population. We are obligated to follow the various studies on heart failure from the developed countries, as we lack national researches and publications. Miqdhaadh et al published a study on etiological aspects of heart failure in patients attending a tertiary cardiac centre of Nepal. ${ }^{2}$ However regarding the study on factors leading to decompensation of heart failure we still lack data. There have been few studies on prevalence and profile of heart failure patients in Nepal. ${ }^{3,4,5}$

As most of the factors leading to decompensation of heart failure are preventable and simple measures can decrease frequent hospitalizations, we aim to identify these factors in patients attending one of the tertiary cardiac centre of Nepal, Department of Cardiology, Manmohan Cardiothoracic Vascular and Transplant Centre (MCVTC), Tribhuwan University.

(a) Nepalese Heart Journal. Nepalese Heart Journal retain copyright and works is simultaneously licensed under Creative Commons Attribution License CC - By 4.0 that allows others to share the work with an acknowledge of the work's authorship and initial publication in this journal 


\section{Methods}

This was a single centre, prospective, observational study from $1^{\text {st }}$ June 2019 to $30^{\text {th }}$ November 2019. Patients who were already diagnosed with heart failure, according to Framingham criteria for heart failure, presented again with decompensated heart failure in the emergency of MCVTC were enrolled in the study. Patients who were suffering from dementia and psychiatric illnesses causing problems in communication and memory were excluded. Patients who were under mechanical ventilator or intubated were also excluded. All patients were included in this study only after they gave consent for history taking, physical examination, and investigations. Questions were asked about their age, sex, diagnosis in their own words, duration of the disease, medications, smoking and alcohol habits, fluid and dietary patterns. Questions were also asked about their attitude towards treatment adherence, doses and names of the drugs if they knew.

Patients were labeled as being poor or noncompliant to diet and fluids if they took salt more than $2 \mathrm{~g} /$ day (one teaspoon $=5 \mathrm{~g}$ was given as a reference) and drank fluid more than 2.5 liters (a plastic mineral water bottle of a liter capacity was given as a reference) in a day and as poorly adherent or noncompliant to treatment if they took medications intermittently or left medications for $\geq 2$ days.

At presentation, thorough history taking and physical examination were done. Relevant investigations to identify ischemia, arrhythmias, infection and other disorders such as anemia, hypo or hyperthyroidism responsible for decompensation of heart failure were also done. Previous discharge records were also checked.

Data were recorded and entered in an excel sheet and analyzed using SPSS version 21 and normality/skewness of data were tested and accordingly descriptive statistics were calculated using mean and standard deviations

\section{Results}

In our study, the total number of patients included was 101 within a duration of six months. The mean age of the patients was 62.81 years $(\mathrm{SD}=15.92)$. The minimum and maximum age of the patients included in our study were 19 years and 91 years respectively. Out of total patients included, $53(52.5 \%)$ were males and 48 (47.5\%) were females as shown in table 1 .

Table 1: Baseline characteristics

\begin{tabular}{ll} 
Characteristics & Number \\
\hline Mean age (SD) (years) & $62.81(15.92)$ \\
\hline Male/female, N (\%) & $53(52.5 \%) / 48(47.5 \%)$ \\
\hline Medications prescribed & \\
Diuretics, N (\%) & $96(95 \%)$ \\
ACEI/ARB, N (\%) & $64(63.3 \%)$ \\
BB, N (\%) & $63(61.3 \%)$ \\
ARA, N (\%) & $81(62.3 \%)$ \\
Digoxin, N (\%) & $38(37.6 \%)$ \\
Amiodarone, N (\%) & $13(12.8 \%)$ \\
CCB, N (\%) & $11(10.8 \%)$ \\
Other, N (\%) & $77(76.2 \%)$
\end{tabular}

\begin{tabular}{|c|c|}
\hline \multicolumn{2}{|l|}{ Comorbidity } \\
\hline HTN, N (\%) & $9(8.9 \%)$ \\
\hline DM,HTN, N (\%) & $29(28.7 \%)$ \\
\hline DM,HTN, Other, N (\%) & $9(8.9 \%)$ \\
\hline DM, Hypothyroidism, N (\%) & $2(1.9 \%)$ \\
\hline CKD, N (\%) & $7(6.9 \%)$ \\
\hline Hypothyroidism, N (\%) & $10(9.9 \%)$ \\
\hline Smoker, N (\%) & $41(40.5 \%)$ \\
\hline Alcoholic, N (\%) & $19(18.8 \%)$ \\
\hline \multicolumn{2}{|l|}{ Rhythm } \\
\hline Sinus rhythm, N (\%) & $65(64.3 \%)$ \\
\hline Arrhythmia, N (\%) & $36(35.6 \%)$ \\
\hline \multicolumn{2}{|l|}{ CXR (chest-X-ray) } \\
\hline Pulmonary congestion, N (\%) & $87(86.1 \%)$ \\
\hline Pneumonia/consolidation, N (\%) & $8(7.9 \%)$ \\
\hline \multicolumn{2}{|l|}{ LVEF } \\
\hline$<40 \%$ & $68(67.3 \%)$ \\
\hline$\geq 50 \%$ & $25(24.7 \%)$ \\
\hline Mean $\mathrm{Hb}(\mathrm{gm} / \mathrm{dl})(\mathrm{SD})$ & $11.42(2.06)$ \\
\hline Mean serum $\mathrm{Na}(\mathrm{mmol} / \mathrm{l})(\mathrm{SD})$ & $137.39(4.2)$ \\
\hline Mean serum $\mathrm{Cr}(\mathrm{mg} / \mathrm{dl})(\mathrm{SD})$ & $1.37(0.59)$ \\
\hline Total leucocyte count (per cumm)(SD) & $8177(3052.5)$ \\
\hline \multicolumn{2}{|l|}{ Etiology } \\
\hline DCM, N (\%) & $52(51.4 \%)$ \\
\hline RHD, N (\%) & $25(24.7 \%)$ \\
\hline ICM, N (\%) & $14(13.8 \%)$ \\
\hline Non rheumatic VHD, N (\%) & $6(5.9 \%)$ \\
\hline HHD, N (\%) & $2(1.9 \%)$ \\
\hline CHD, N (\%) & $2(1.9 \%)$ \\
\hline \multicolumn{2}{|l|}{ NYHA (New York Heart Association) class } \\
\hline IV, N (\%) & $76(75.2 \%)$ \\
\hline III, N (\%) & $19(18.8 \%)$ \\
\hline II, N (\%) & $6(5.9 \%)$ \\
\hline $\begin{array}{l}\text { ACEI-angiotensin converting enzyme } \\
\text { receptor blocker, ARA-aldosterone receptor } \\
\text { CCB-calcium channel blocker, CHD-cong } \\
\text { chronic kidneydisease, Cr-creatinine, DM-di } \\
\text { cardiomyopathy,HHD-hypertensive heart } \\
\text { RHD-rheumatic heart disease, ICM-isch } \\
\text { sodium, VHD-valvular heart disease. }\end{array}$ & $\begin{array}{l}\text { inhibitor, ARB-angiotensin } \\
\text { antagonist, BB-betablocker, } \\
\text { enital heart disease, CKD- } \\
\text { abetes mellitus, DCM-dilated } \\
\text { disease, HTN-hypertension, } \\
\text { emic cardiomyopathy, Na- }\end{array}$ \\
\hline
\end{tabular}
sodium, VHD-valvular heart disease. 
As mentioned in table 1, at presentation to our hospital, most of the patients $(75.2 \%)$ presented in NYHA class IV followed by NYHA class III $(18.8 \%)$ and class II $(5.9 \%)$. On evaluation it was found that about $95 \%$ of patients were prescribed with diuretics and with ACEI/ARB (63.3\%), beta-blockers $(61.3 \%)$, aldosterone antagonists $(62.3 \%)$, digoxin $(37.6 \%)$, amiodarone $(12.8 \%)$, calcium channel blockers $(10.8 \%)$. Among those 11 patients under calcium channel blocker, $81.8 \%$ were taking amlodipine (dihydropyridine) and remaining were taking diltiazem (nondihydropyridine).

Of all patients included, $8.9 \%$ patients had HTN only as comorbidity whereas $28.7 \%$ had both HTN and DM, 8.9\% had HTN, DM along with other comorbidities, $1.9 \%$ had DM and hypothyroidism. About $6.9 \%$ of patients had chronic kidney disease not under renal replacement therapy. There was a history of hypothyroidism only in $9.9 \%$ of patients. About $40.5 \%$ of patients were smokers and $18.8 \%$ were alcohol consumers.

ECG showed that $65(64.3 \%)$ patients were in sinus rhythm. Chest radiography revealed that about $86.1 \%$ of patients had evidence of pulmonary congestion and $7.9 \%$ of patients had findings suggestive of consolidation. The baseline echocardiographic evaluation showed that about $67.3 \%$ of total patients had reduced ejection fraction $(<40 \%)$ and $24.7 \%$ had preserved ejection fraction ( $\geq 50 \%)$ and remaining patients had ejection fraction between $40-49 \%$ as mentioned in table 1. Etiologically, about $51.4 \%$ of patients had dilated cardiomyopathy, $24.7 \%$ patients had rheumatic heart disease, $13.8 \%$ had ischemic cardiomyopathy as supported by past history of the acute coronary syndrome and left ventricular systolic dysfunction, 5.9\% patients had non rheumatic valvular heart disease, $1.98 \%$ of patients had hypertensive heart disease and $1.9 \%$ had congenital heart disease as mentioned in table 1 .

Table 2: Factors responsible for acute decompensated heart failure.

\begin{tabular}{|l|l|}
\hline Factors leading to decompensation & $\begin{array}{l}\text { Number of } \\
\text { patients }(\%)\end{array}$ \\
\hline $\begin{array}{l}\text { Poor compliance to medications and diet } \\
\text { and fluid restrictions }\end{array}$ & $39(38.6 \%)$ \\
\hline Arrhythmia & $36(35.6 \%)$ \\
\hline Infection & $13(12.9 \%)$ \\
\hline Anemia & $5(4.9 \%)$ \\
\hline Ischemia & $3(2.9 \%)$ \\
\hline No factors identified & $5(4.9 \%)$ \\
\hline
\end{tabular}

Regarding factors responsible for decompensation of heart failure as shown in table 2 the most common factor leading to decompensation of heart failure found in our study was poor compliance to medications and diet, which was responsible for decompensation in about $38.6 \%$ of total patients included in this study. In this group, $28(71.8 \%)$ patients were poorly compliant to medications and $11(28.2 \%)$ patients were poorly compliant to diets and fluid restriction. Of 28 patients, 10 (35.7\%) patients left taking diuretics, 9 (32.1\%) patients left taking beta-blockers and diuretics and the remaining $9(32.1 \%)$ patients left taking all the medications prescribed for heart failure at the previous visit (Figure 1). Of those 11 patients who were poorly compliant to diets and fluids, 7 patients gave a history of excessive oral fluid intake for decreased urine output and 5 patients were unaware of the dietary advice.
Figure 1: Percentage depicting non-compliance to medications at presentation to hospital.

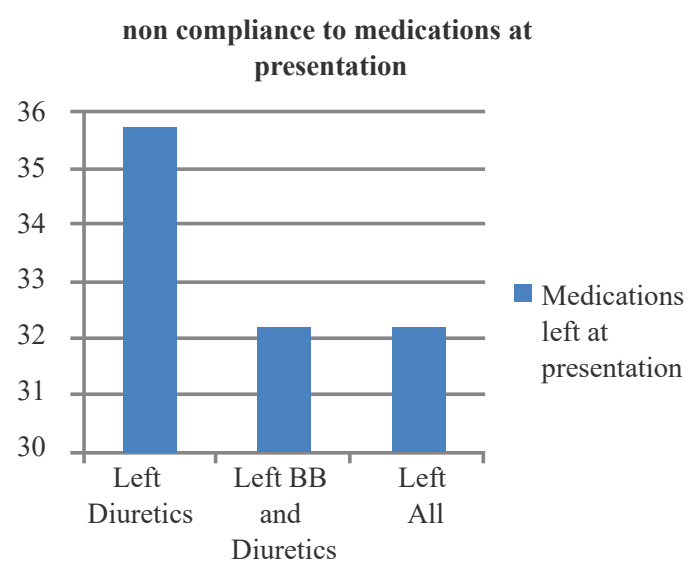

Figure 2: Various arrhythmias responsible for decompensation.

\section{Arrhythmias}

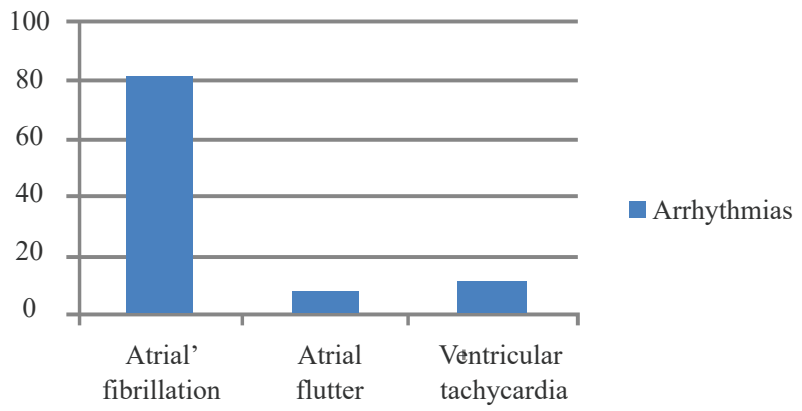

Following poor compliance with medications and diet and fluid restrictions, arrhythmia was the next most common factor which was detected in about $35.6 \%$ of patients. Of these 36 patients, $29(80.5 \%)$ patients sustained atrial fibrillation with fast ventricular rate and 3 $(8.3 \%)$ patients had atrial flutter. (Figure 2$)$ the remaining $4(11.1 \%)$ had sustained ventricular tachycardia of which three were electrically cardioverted to sinus rhythm and the remaining one with amiodarone.

Figure 3: Various infections responsible for decompensation

Infections

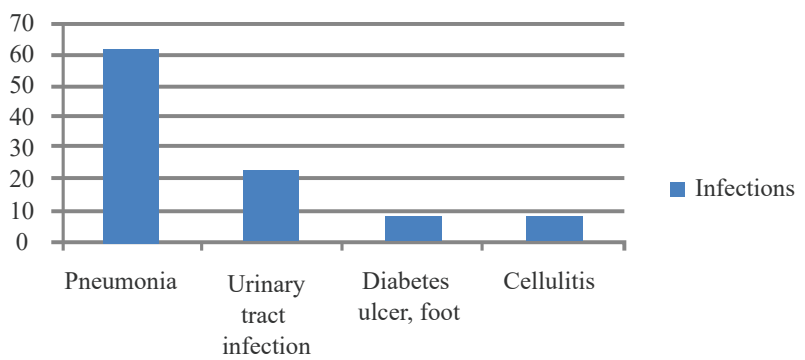


The third most common factor identified was infection as shown in figure 3 in about $12.9 \%$ of patients. Of 13 patients in this group, $8(61.5 \%)$ patients had evidence of community-acquired pneumonia as evidenced by chest $\mathrm{x}$-ray findings of consolidation supported by fever and raised total leucocyte counts. Out of these 8 patients with pneumonia two patients had positive sputum culture isolating klebsiella pneumonia. None of these pneumonia patients had positive blood culture. Three patients $(23 \%)$ had a urinary tract infection in which two patients had positive urine culture reports isolating E.coli. One patient $(7.7 \%)$ had a diabetic ulcer in the right foot who showed positive wound swab culture isolating staphylococcus. And the remaining one had cellulitis of left leg diagnosed clinically in conjunction with raised total leucocyte count of $17000 / \mathrm{mm}^{3}$.

In about $4.9 \%$ of total patients, severe anemia (hemoglobin less than $7 \mathrm{gm} / \mathrm{dl}$ ) was found to be responsible for decompensation of heart failure. In $2.9 \%$ of the total patients included in this study had evidence of acute myocardial ischemia. All these patients had nonSTEMI at presentation. In about $4.9 \%$ of patients, we could not identify any obvious factors leading to decompensated heart failure.

\section{Discussion}

Heart failure is a major health problem. Its incidence rises as age advances. Though there are various advances in the treatment of heart failure, its mortality still remains high. ${ }^{6}$

The increasing life expectancy and advances in the treatment of cardiac diseases have probably resulted in an increased number of patients with heart failure, especially the elderly population. So in a country like Nepal which falls under the category of developing nations, finding the factors which are likely to cause decompensation of heart failure can decrease the overall cost of treatment and readmission into the hospitals by simple measures. Patients who are once admitted for treatment of heart failure have a higher risk of readmission due to decompensation because of various factors. ${ }^{7}$

In OPTIMIZE-HF registry, common factors related to decompensation were pneumonia $(15.3 \%)$, ischemia $(14.7 \%)$ and arrhythmia (13.5\%). ${ }^{8}$ In Euro Heart failure survey II, acute coronary syndrome, arrhythmia and valvular dysfunctions each were found as precipitants of heart failure in about one-third of the cases. ${ }^{9}$ In a study published by Ghali et al, where the mean age of the patients was 59 years, the most common factor leading to decompensation was found to be: poor compliance to medications prescribed (64\%). Cardiac arrhythmia was found in $29 \%$ and pulmonary infection was found in $12 \%$ of the cases. ${ }^{10}$ In a study done by Wagdi and coworkers in Switzerland, again the most common factor implicated was non-compliance in about $47 \%$ of cases included. The mean age of patients included in this study was 76 years. Arrhythmia, ischemia and infection were found in $14 \%, 14 \%$ and $6 \%$ of cases respectively. ${ }^{11}$ In a study published by Michaelsen et al, the lack of adherence to the prescribed medical regimen was the most common factor $(41.9 \%)$ identified to cause acute decompensation of heart failure. The mean age of patients included in this study was 75.4 years. Other factors related to decompensation were coronary ischemia $(13.4 \%)$, and arrhythmia $(6.1 \%){ }^{12}$ In a study conducted in a South American community hospital, which included 102 patients with a mean age of 79 years, the most common precipitant of heart failure identified was non-compliance with diet in about $52 \%$ cases. Infections, arrhythmias, and ischemia were found in $29 \%, 25 \%$ and $22 \%$ of the cases. ${ }^{13}$

In our study, mean age of the patients included was 62.81 years which seems to be younger than most of the population studied in other countries which could be related to the factors like the higher prevalence of rheumatic heart disease, poor health care system of our country and low socioeconomic status of the majority population.
As in most of the studies published to date, the most common factor responsible for acute decompensation of heart failure was poor compliance with medications and diet in $38.6 \%$ of cases. In $71.8 \%$ of cases poor compliance with medications was found in this category. $28.2 \%$ were poorly compliant to diets and fluid intake.

Arrhythmia was also implicated in the majority of cases $(35.6 \%)$, mostly atrial fibrillation with a fast ventricular rate. A higher incidence of arrhythmia could be attributed to a lack of adherence to the medical regimen again. Infection (12.9\%) was the third most factor identified in our study, most being chest infection/pneumonia. Severe anemia was found in $4.9 \%$ of cases. This could be attributed to poor socioeconomic status leading to inadequate nutritional support and in part the progression of the disease itself and comorbidities like chronic kidney disease.

Ischemia as a precipitant was found only in $2.9 \%$ of the cases. The less bulk of ischemia as a precipitant could be attributed to the availability of revascularization strategy in our centre for patients with coronary artery disease leading to fewer complications on further visits and could have been, in part, because of undetectable ischemia as well. We could not identify any precipitants in $4.9 \%$ of patients. The decompensation in these patients could be because of disease progression itself or the evaluation could be incomplete in this set of patients due to various reasons like financial constraints, patient's denial and inadequate evaluation of the disease.

\section{Conclusion}

As in most of the studies, poor compliance with medications, diet, and fluid is the most common factor leading to acute decompensation of heart failure in our centre. Next to it was arrhythmia which could again be attributed to, in part, the lack of adherence to the medical regimen prescribed. The most effective way of reducing such preventable factors of decompensation would be adequate patient counseling. Identifying such preventable factors and addressing them can decrease recurrent hospital admissions and economic burden to the patient and government as well.

\section{Limitations of the study}

The main limitations of this study are small sample size and short time period, lack of differentiation between heart failure with preserved and reduced ejection fraction, lack of blood tests such as brain natriuretic peptide and high sensitivity troponin. The other limitation is that the immunization status of patients has also not been taken into consideration.

\section{Acknowledgment}

We would like to thank Professor Dr. Arun Sayami (Head of Department, Cardiology), Professor Dr. Sunil Chandra Jha and Dr. Subarna Mani Acharya for their continuous support and guidance.

\section{Conflict of Interest: None}

\section{References}

1. James L., Jannuzi JR, Douglas LM, Approach to the patient with heart failure, In:Zipes DP, Libby P, Bonow RO, Mann DL, Tomaselli GF. Braunwald's Heart Disease E-Book: A Textbook of Cardiovascular Medicine,11th edition,Elsevier Health Sciences; 2018 Jan 9.p.403-414

2. Shareef M, KC MB, Raut R, et al. Etiology of heart failure in the emergency department of a tertiary cardiac centre of 
Nepal. Nepalese Heart Journal. 2017 Nov 1;14(2):1-4. https:// doi.org/10.3126/njh.v14i2.18494

3. Dubey L, Sharma SK, Chaurasia AK. Clinical profile of patients hospitalized with heart failure in Bharatpur, Nepal. Journal of cardiovascular and thoracic research. 012;4(4):103.

4. Shakya S, Sharma D, Bhatta YD. Current scenario of heart diseases in Nepal: At a glance. Nepalese Heart Journal. 2011; 8(1):23-6. https://doi.org/10.3126/njh.v8i1.8333

5. Shrestha UK, Alurkar VM, Baniya R, et al. Profiles of heart failure in the western region of Nepal: prognostic implications of the MELD-XI score. Internal Medicine Inside. 2015 Mar 7;3(1):1. https://doi.org/10.7243/2052-6954-3-1

6. Ho KK, Pinsky JL, Kannel WB, el.at. Oct. 1993;22 (4 Suppl A): $6 \mathrm{~A}-13 \mathrm{~A}$. The epidemiology of heart failure: the Framingham Study. https://doi.org/10.1016/0735-1097(93)90455-A

7. Adams Jr KF, Fonarow GC, Emerman CL, et al. ADHERE Scientific Advisory Committee and Investigators. Characteristics and outcomes of patients hospitalized for heart failure in the United States: rationale, design, and preliminary observations from the first 100,000 cases in the Acute Decompensated Heart Failure National Registry (ADHERE). American heart journal. 2005 Feb 1;149(2):209-16. https://doi.org/10.1016/j. ahj.2004.08.005. PMid:15846257

8. Fonarow GC, Abraham WT, Albert NM, et al. Factors ident ified as precipitating hospital admissions for heart failure and clinical outcomes: findings from OPTIMIZE-HF. Archives of internal medicine. 2008 Apr 28;168(8):847-54. https://doi.org/10.1001/archinte.168.8.847. PMid:18443260

9. Nieminen MS, Brutsaert D, Dickstein K, et al. EuroHeart Failure Survey II (EHFS II): a survey on hospitalized acute heart failure patients: description of population. European heart journal. 2006 Sep 25;27(22):2725-36. https://doi. org/10.1093/eurheartj/ehl193. PMid:17000631

10. Ghali JK, Kadakia S, Cooper R, Ferlinz J. Precipitating factors leading to decompensation of heart failure: traits among urban blacks. Archives of internal medicine. 1988 Sep 1;148(9):2013-6. https://doi.org/10.1001/archinte.148.9.2013 PMid:3046541

11. Wagdi P, Vuilliomenet A, Kaufmann U, et al. Inadequate treatment compliance, patient information and drug prescription as causes for emergency hospitalization of patients with chronic heart failure. Schweizerischemedizinische Wochen schrift. 1993 Jan;123(4):108-12.

12. Michalsen A, König G, Thimme W. Preventable causative factors leading to hospital admission with decompensated heart failure. Heart. 1998 Nov 1;80(5):437-41. https://doi. org/10.1136/hrt.80.5.437. PMid:9930040 MCid:PMC1728853

13. Diaz A, Ciocchini C, Esperatti M, et al. Precipitating factors leading to decompensation of chronic heart failure in the elderly patient in South-American community hospital. Journal of geriatric cardiology: JGC. 2011 Mar;8(1):12. https://doi.org/10.3724/SP.J.1263.2011.00012. PMid:22783279. PMCid:PMC3390061 